\title{
Health-related quality of life following heart surgery
}

\author{
Redoy Ranjan, Dipannita Adhikary, Sanjoy Kumar Saha and Asit Baran Adhikary
}

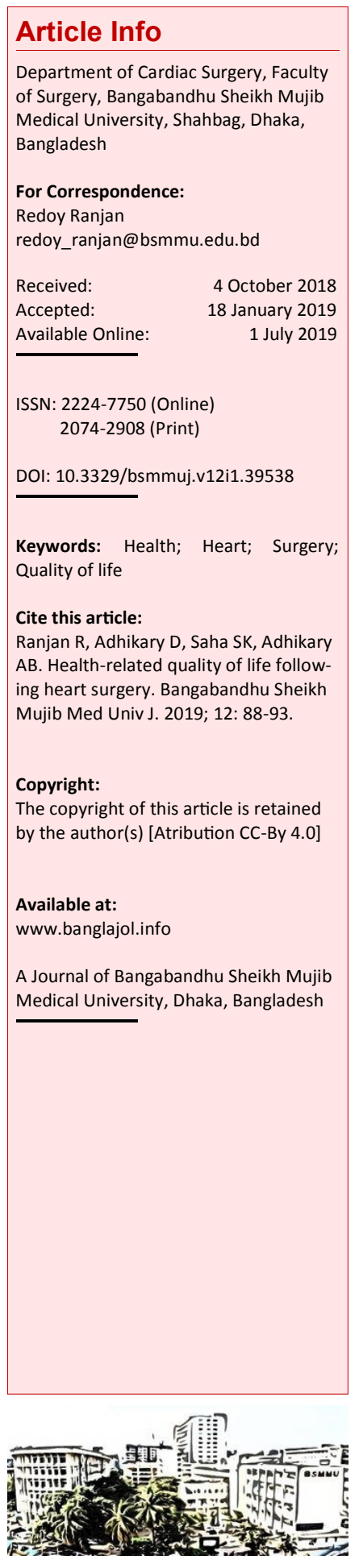

\section{Abstract}

This study evaluates the differences in preoperative and postoperative health-related quality of life of the patients following heart surgery and observed the factors that influence quality of life changes. This prospective observational study involved two parameters from the SF-36 questionnaire before and one year after heart surgery in a single surgeon's practice. At the baseline assessment of the study observed 140 patients, predominantly were male in both study groups. The mean age was $56.8 \pm 4.2$ years, $64.7 \pm 7.4$ years in Group of patients age $\leq 60$ years and age $>60$ year's respectively. In elderly aged group, patients have greater risk of co-morbidity, operative complications, and low preoperative as well as postoperative quality of life score. There was an overall improvement in all majority health domains of the SF-36 questionnaire among study population. Statistical results from Logistic multivariate analysis demonstrates a greater value of preoperative mental component summary scores $(\mathrm{p}=0.08)$, and physical component summary scores $(\mathrm{p}=0.01)$ as potential risk factors for non-improvement following heart surgery. Although, elderly patients (age $>60$ year's) with greater operative risk have low preoperative quality of life score, but demonstrate an equal improvement in most of the health domains following heart surgery as like as younger study population.

\section{Introduction}

Health-related quality of life is an issue of great importance especially for the end result of any surgical procedures.1 Concurrently people's life span has gone up specifically in recent years, as well as there are a significant number of aged population who are undergoing heart surgery.? For calculating the morbidity and mortality while the cardiac surgery is done, age is an autonomous factor to predict the outcome. $\frac{3,4}{4}$ However, as the elderly patients are more prone to suffer from postoperative comorbidities, if the operative time is more as well as due to their low physiological reserves. .5 Different types of conclusion have been made in the studies on postoperative health related quality of life based on age factors. However, in presence of controversial statement, it has been not absolutely certified that there is an effect of age on postoperative health-related quality of life status. $\underline{5-7}$

The most common postoperative comorbidities following heart surgery are infection, arrhythmia, neurological impairment as well as renal and respiratory functional impairment. 8 A higher incidence of preoperative red cell transfusion to older patients may results in a reduced tolerance of hypohemoglobinemia after surgery and insufficient activity of the hematopoietic system.9,10 Moreover, a high incidence of red cell unit's transfusion has been identified as an independent predicting factor in postoperative mortality; but there is insufficient data regarding the impact of postoperative morbidities on health-related quality of life score. $\underline{11}$

The SF-36 questionnaire is often used as a tool for assessing the quality of life in various medical fields, where it is valued especially for its ability to capture the social dimensions of life. $\underline{\underline{12}}$ In cardiology, for example, it has been used in patients with ischemic heart disease, in the course of heart failure, or in the presence of atrial fibrillation. $\underline{13,14}$ Furthermore, in cardiac surgery an assessment of health-related quality of life by means of using the SF-36 questionnaire in patients undergoing myocardial revascularization surgery, heart valves repair or replacement and surgery involves thoracic aorta, and intracardiac repair for congenital abnormalities was carried out. $\underline{10,12-15}$

The aim of this study was to assess the influence of age on health-related quality of life among two study groups by using the SF-36 questionnaire and also to compare clinical data from the preoperative, perioperative, and postoperative periods experienced by these groups. A second aim was to identify the group of patients who do not benefit from the surgery (non-improvers) and to find potential risk factors for unimproved quality of life after heart surgery for further clinical research. 


\section{Materials and Methods}

A total of 140 patients were evaluated at the Cardiothoracic Surgery Department in a single surgeon practice in the period from January 2015 to December 2016. The study population inclusion criteria were informed written consent, study participation agreement, and elective cardiac surgery. On the other hand, refusal of the patients to participate, complex congenital as well as emergency heart surgery were excluded from this study. A SF36 questionnaire was also completed before and one year after heart surgery. There are 8 (eight) domains in SF-36 questionnaire which covers social, physical and mental life of each individuals and was applied to assess the health related quality of life for the study populations. These eight domains are known as follows: Role physical, physical functioning,

\section{Table I}

\section{Pre- and perioperative variables of the study population}

\begin{tabular}{|c|c|c|}
\hline \multirow[t]{2}{*}{ Variables } & $\begin{array}{c}\text { Age } \leq 60 \text { years } \\
\quad(\mathrm{n}=84)\end{array}$ & $\begin{array}{c}\text { Age }>60 \text { years } \\
\quad(n=56)\end{array}$ \\
\hline & $\%$ & $\%$ \\
\hline \multicolumn{3}{|l|}{ Preoperative variables } \\
\hline Age (years) & $56.8 \pm 4.2$ & $64.7 \pm 7.4$ \\
\hline \multirow{3}{*}{$\begin{array}{l}\text { Male } \\
\text { Female }\end{array}$} & 73.8 & 53.6 \\
\hline & 26.2 & 46.4 \\
\hline & 60.7 & 80.4 \\
\hline $\begin{array}{l}\text { Prior percutaneous coronary interven- } \\
\text { tion }\end{array}$ & 16.7 & 10.7 \\
\hline History of myocardial infarction & 14.3 & 12.5 \\
\hline Arrhythmia & 13.1 & 32.1 \\
\hline Diabetes mellitus & 22.6 & 39.2 \\
\hline Renal dysfunction & 13.1 & 26.8 \\
\hline Chronic obstructive pulmonary disease & 14.3 & 8.9 \\
\hline History of cerebrovascular accident & 4.8 & 16.1 \\
\hline Cerebral vascular disease & 7.1 & 19.6 \\
\hline Peripheral artery disease & 4.8 & 5.4 \\
\hline Reoperation & 6.0 & 5.4 \\
\hline Anemia & 3.6 & 12.5 \\
\hline EuroSCORE & $4.3 \pm .78$ & $10.5 \pm 1.2$ \\
\hline Left ventricular ejection fraction (\%) & $59.6 \pm 11.6$ & $60.9 \pm 10.2$ \\
\hline \multicolumn{3}{|l|}{ Perioperative variables } \\
\hline Coronary artery bypass graft & 66.7 & 67.9 \\
\hline Valve surgery & 25 & 23.2 \\
\hline Combined procedures & 8.3 & 8.9 \\
\hline Total anesthesia time (min) (mean \pm SD) & $244.5 \pm 50.5$ & $247.2 \pm 48.5$ \\
\hline $\begin{array}{l}\text { Cardiopulmonary bypass time (min) } \\
\text { (mean } \pm \mathrm{SD})\end{array}$ & $77.5 \pm 35.4$ & $81.2 \pm 28.5$ \\
\hline Aortic cross-clamp time (min) & $58.0 \pm 25.6$ & $57.7 \pm 21.3$ \\
\hline Mortality & 0 & 0 \\
\hline
\end{tabular}

social functioning, role emotional, mental health, bodily pain, vitality and also general health. Patients answer in response to SF-36 questionnaire, are then transformed on a scale of $0-100$ for individual domains, where zero is worst and 100 is the best health status. Moreover, for interpreting the SF-36 questionnaire a standardized technique was used, and all variables including preoperative, perioperative and postoperative data were collected from authorized medical evidence.

Population were divided into two study groups (age $\leq 60$ years and age $>60$ years) and an assessment utilizing health-related quality of life questionnaire were performed one year after surgery. Furthermore, the SF-36 score were divided into 2 meta score- physical component summary (PCS) score and mental component summary (MCS) score. MCS includes social functioning, role emotional, and mental health. PCS includes role physical, physical functioning, bodily pain, vitality and general health. These two sub-scores have used for multivariate analysis and the SF-36 considered from the SF-36 questionnaire, which represented the mental and physical status of study population. However, improvers and non-improvers population were defined when health related quality of life difference between preoperative and postoperative score was $>0$ and $\leq 0$ respectively in both MCS and PCS scores.

\section{Statistical analysis}

Chi-squared test and un-paired t-test were utilized to analyze the differences between subgroups, and also observed health-related quality of life relationship between survivors and non-survivors of the study population. Non-parametric Wilcoxon matched-pairs signed-rank test was utilized to evaluate the health-related quality of life differences between the before and after surgery. In this study p-values $\leq 0.05$ was considered statistically significant, as well as the logistic regression model utilized for multivariate analysis to evaluate the relationship among preoperative characteristics (age, sex, preoperative MCS and PCS, surgery) and postoperative improvement in health-related quality of life status that is a positive rise in SF-36 score. Online www. euroscore.org utilized to calculate patients risk score, and statistical analyses were performed using SPSS (Statistical Package for the Social Sciences) version 22.

\section{Results}

Preoperative study variables of the study patients are shown in Table I. Male patients were predominant in both study groups and the mean age was significantly higher $(p \leq 0.05)$ in the older aged group (age $>60$ years). This observed a higher prevalence of preoperative diabetes $(\mathrm{p}=0.03)$, arrhythmia 
Table II

Postoperative complications and additionally assessed variables

\begin{tabular}{|lcc|}
\hline Variables & $\begin{array}{c}\text { Age } \leq 60 \text { years } \\
(\mathrm{n}=84)\end{array}$ & $\begin{array}{c}\text { Age }>60 \text { years } \\
(\mathrm{n}=56)\end{array}$ \\
\hline Inotropic drug support required & 33 & 26 \\
Myocardial infarction & 2 & 1 \\
TIA/ Stroke & 1 & 6 \\
Supraventricular arrhythmia & 33 & 29 \\
Ventricular arrhythmia & 3 & 2 \\
Renal failure & 3 & 8 \\
Infection & 8 & 14 \\
Re-exploration for bleeding & 3 & 2 \\
Ventilation problems & 4 & 4 \\
Sternal wound infection & 3 & 2 \\
Blood transfusion (units) & $1.5 \pm 0.5$ & $2.5 \pm 0.5$ \\
Platelets (units) & $0.5 \pm 0.0$ & $0.8 \pm 0.0$ \\
Fresh frozen plasma (units) & $1.6 \pm 0.2$ & $2.4 \pm 0.3$ \\
Median intensive care unit stay (hours) & $38.2 \pm 0.5$ & $39.1 \pm 0.8$ \\
Median hospital stay (days) & $9.5 \pm 1.5$ & $10.0 \pm 1.5$ \\
\hline
\end{tabular}

$(p=0.006)$, renal dysfunction $(p=0.04)$, cerebrovascular disease $(p=0.026)$, and also anemia $(p=0.046)$ in the older age group. The mean EuroSCORE was also significantly higher $(\mathrm{p}<0.001)$ in older age group. However, there were no significant statistical differences in cardiopulmonary bypass as well as aortic cross-clamp time, and anesthesia times between the two study groups of patients (Table I). However, postoperative adverse outcome like the prevalence of stroke or TIA $(p=0.011)$, renal failure $(p=0.021)$, ICU stay $(p=<0.0001)$, infection $(p=0.013)$, and also hospital stay $(\mathrm{p}=0.05)$ were also higher in the older age population (Table II). Moreover, the total number of packed red blood cells, platelets, and FFP transfusion was also statistically significant in the older group $(\mathrm{p}<0.0001)$.

Completed SF-36 questionnaires were returned from $116(82.86 \%)$ patients 1-year after surgery and utilized for the statistical analysis. Unreturned SF-36 questionnaires from 15 patients as well as incomplete SF-36 questionnaires from another 9 patients (5 patients died during study period, and 4 patients did not return the questionnaire) were not considered in the statistical analysis. The statistical results of preoperative and postoperative SF-36 scores difference are presented in Table III. After surgery, the SF-36 scores of the study population improved significantly in all 8 health domains: Role physical, physical functioning, bodily pain, vitality, general health, role emotional, social functioning, and also mental health. Moreover, SF-36 scores differences for evaluation of health-related quality of life were also compared according to age (age $\leq 60$ years and $>60$ years) of study patient's. Preoperative SF-36 scores for health-related quality of life were slightly greater in young population (Table III), and observed a higher difference of SF-36 scores between before and after surgery health-related quality of life domains in the study group age $>60$ years.

During analysis of the preoperative SF-36 questionnaire, we observed significant differences in all health-related quality of life domains between the subgroups of survivors and non-survivors (Figure $1)$. This study revealed, only $14.66 \%$ patients are non-improvers, and $85.34 \%$ of patients improved in both or either PCS and MCS scores of health-related quality of life domain. The study variables of improvers and non-improvers population are listed in Table IV. In total, 99 (85.7\%) patients improve their health-related quality of life following heart surgery which is statistically significant $(p \leq 0.05)$. Furthermore, statistical analysis also demonstrates

\begin{tabular}{|c|c|c|c|c|c|c|c|c|c|c|}
\hline \multicolumn{11}{|c|}{ Table III } \\
\hline \multicolumn{11}{|c|}{ SF-36 scores of the study population } \\
\hline \multirow[t]{2}{*}{ Sub-score } & \multicolumn{2}{|c|}{$\begin{array}{l}\text { Before surgery } \\
\qquad(\mathrm{n}=116)\end{array}$} & \multicolumn{2}{|c|}{$\begin{array}{l}\text { One year after surgery } \\
\qquad(\mathrm{n}=116)\end{array}$} & \multirow[t]{2}{*}{$\mathrm{p}$ value } & \multicolumn{2}{|c|}{$\begin{array}{c}\text { Age } \leq 60 \text { years } \\
\quad(\mathrm{n}=71)\end{array}$} & \multicolumn{2}{|c|}{$\begin{array}{l}\text { Age }>60 \text { years } \\
\quad(n=45)\end{array}$} & \multirow[t]{2}{*}{$\mathrm{p}$ value } \\
\hline & Mean & SD & Mean & SD & & Difference & SD & Difference & $\mathrm{SD}$ & \\
\hline Physical functioning & 47.1 & 27.1 & 64.5 & 23.1 & $<0.0001$ & 16.3 & 30.1 & 22.4 & 28.5 & 0.2800 \\
\hline Role physical & 27.7 & 36.2 & 50.2 & 37.9 & $<0.0001$ & 21.6 & 48.7 & 26.8 & 49.7 & 0.5793 \\
\hline Bodily pain & 58.2 & 24.9 & 72.8 & 22.5 & $<0.0001$ & 10.8 & 30.3 & 20.1 & 31.6 & 0.1159 \\
\hline General health & 45.8 & 16.1 & 52.7 & 18.8 & 0.0030 & 5.1 & 23.2 & 7.5 & 18.5 & 0.4170 \\
\hline Vitality & 47.2 & 18.8 & 56.4 & 17.8 & 0.0002 & 9.2 & 22.3 & 11.7 & 21.2 & 0.5500 \\
\hline Social functioning & 65.1 & 21.1 & 72.5 & 21.6 & 0.0089 & 7.1 & 28.2 & 11.1 & 27.2 & 0.4520 \\
\hline Role emotional & 43.5 & 43.4 & 66.8 & 36.4 & $<0.0001$ & 23.8 & 51.2 & 31.7 & 48.6 & 0.4107 \\
\hline Mental health & 58.6 & 19.4 & 69.5 & 15.8 & $<0.0001$ & 8.9 & 20.8 & 14.6 & 20.8 & 0.1531 \\
\hline
\end{tabular}


Table IV

Characteristics of improvers and non-improvers study population following heart surgery

\begin{tabular}{|lccc|}
\hline Variables & $\begin{array}{c}\text { Improvers } \\
(\mathrm{n}=99)\end{array}$ & $\begin{array}{c}\text { Non- } \\
\text { improvers } \\
(\mathrm{n}=17)\end{array}$ & p value \\
\cline { 2 - 3 } & Mean \pm SD & Mean \pm SD & \\
\hline Age & $61.6 \pm 5.5$ & $60.2 \pm 7.1$ & 0.3149 \\
Body mass index & $27.2 \pm 3.5$ & $29.0 \pm 2.5$ & 0.0291 \\
Intensive care unit stay (days) & $2.1 \pm 1.5$ & $3.2 \pm 1.5$ & 0.0012 \\
Hospital stay (days) & $9.0 \pm 2.5$ & $10.5 \pm 3.5$ & 0.0002 \\
Ejection fraction (\%) & $60.5 \pm 8.4$ & $61.1 \pm 8.6$ & 0.7686 \\
Preoperative MCS & $53.1 \pm 24.1$ & $75.8 \pm 21.1$ & 0.0001 \\
Postoperative MCS & $72.8 \pm 17.7$ & $53.1 \pm 21.2$ & $<0.0001$ \\
Preoperative PCS & $41.5 \pm 22.3$ & $65.5 \pm 21.5$ & $<0.0001$ \\
Postoperative PCS & $65.5 \pm 22.2$ & $45.1 \pm 19.1$ & $<0.0001$ \\
PCS- Physical component summary; MCS- Mental component summary & \\
\hline
\end{tabular}

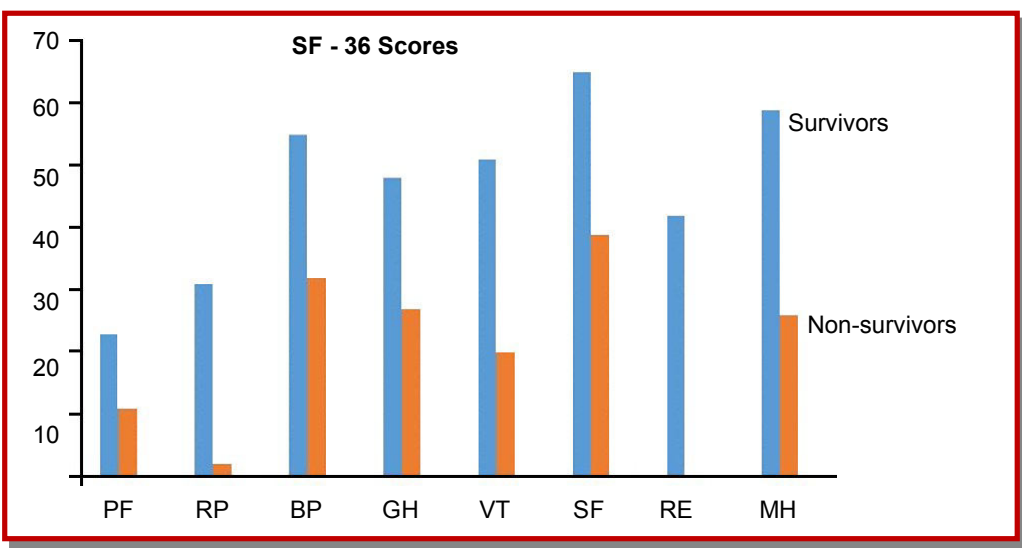

Figure 1: SF-36 score differences in preoperative health-related quality of life among survivors and non-survivors.

Note: Physical functioning (PF), role physical (RP), bodily pain (BP), general health $(\mathrm{GH})$, vitality $(\mathrm{VT})$, social functioning $(\mathrm{SF})$, role emotional (RE), mental health $(\mathrm{MH})$

\begin{tabular}{|c|c|c|c|c|}
\hline \multicolumn{5}{|c|}{ Table V } \\
\hline \multicolumn{5}{|c|}{$\begin{array}{l}\text { Multivariate analysis on effect of preoperative MCS and PCS } \\
\text { scores on postoperative improvement of quality of life }\end{array}$} \\
\hline Variable & $\begin{array}{c}\text { Regression } \\
\text { coefficient }\end{array}$ & Odds ratio & $\begin{array}{c}\text { Confidence } \\
\text { interval (95\%) }\end{array}$ & $p$ value \\
\hline Age $>60$ years & - & - & - & \\
\hline Gender & - & - & - & \\
\hline Type of surgery & - & - & - & \\
\hline Preoperative MCS & 0.023 & 1.03 & $0.998-1.01$ & 0.0850 \\
\hline Preoperative PCS & 0.027 & 1.04 & $1.01-1.06$ & 0.0191 \\
\hline
\end{tabular}

that BMI, duration of both ICU and hospital stays, physical component summery and mental component summery were significantly higher $(p \leq 0.05)$ in non-improver group of study population. Multivariate analysis observed that only preoperative health-related quality of life status was a strong predicting factor that associated with significant non-improvement in quality of life following surgery (Table V). Furthermore, patients having higher preoperative PCS and MCS scores greatly influenced the non-improvement in postoperative healthrelated quality of life status.

\section{Discussion}

The principal observation of this study was the results from multivariate analysis, where the provided variables like age, sex, nature of surgery, as well as preoperative PCS and MCS score were evaluated to demonstrates the influence on improvement and non-improvement of health-related quality of life status following heart surgery. Logistic multivariate analysis has shown that, only preoperative data of PCS and MCS score has potential influence on postoperative health-related quality of life changes following heart surgery. The greater chance of improvement in postoperative health related quality of life was observed in patients with lower PCS and MCS scores before operation. This study also shown that survivors had a significantly higher preoperative health-related quality of life score in contrast to non-survivors.

Several published article has demonstrated that the most common postoperative morbidities in elderly group of patients are heart failure, ventricular dysfunction, arrhythmia, hemorrhage, respiratory as well as renal function impairment, and also neurological disorders. $2-5$ In this study, there were also higher incidences of respiratory as well as urinary tract infections and also greater numbers of red cell transfusion given in the elderly group of patients age $>60$ years which is concordance to other study results. $.6-8$ Moreover, in a study, Frelich et al. (2003) found that elderly patients age $>70$ years required about $15 \%$ greater hospital costs in comparison to young patient. 9 However, Engoren et al. (2002) analyzed the unique clinical situation and they also found that hospital costs was much higher in elderly population (especially $>80$ years) due to postoperative adverse effects. 10 According to their study results, the treatment costs for elderly patients are significantly higher than are those for younger patients, which is also similar to others findings. $.8,11-14$ At present, socioeconomic view on medical practice is rising more significantly in daily practice, and physician's efforts should be directed towards the high-risk patients as because majority of the postoperative adverse effects are interlinked to preoperative clinical status. Furthermore, incidence of postoperative morbidities can be diminished by providing proper preoperative optimization, meticulous surgical techniques, and standard 
postoperative care.10-15 As like other discipline, in cardiac surgery, there should be continuity to develop newer surgical techniques especially minimally invasive procedure, endovascular surgery etc. that are particularly dedicated to elderly population and which methods reduces the chance of postoperative morbidities as well as mortality..$\underline{5,16,17}$

In a study, Hansen et al. (2010) observed two components both mental and physical status of the SF-36 questionnaire among the survivor and nonsurvivor patients at first 6 months following coronary artery bypass graft surgery. $1 \underline{18}$ The study results shown that the preoperative clinical condition was the major influencing factor to change in health related quality of life following surgery. Preoperative factors associated with failure to improve postoperative health-related quality of life score are as follows: preoperative comorbidities and postoperative low cardiac output, left ventricular dysfunction, low ejection fraction, a NYHA functional class 3 or 4 , new onset of arrhythmia after surgery, pulmonary hypertension, previous heart surgery, and also history of myocardial infarction.12, 17-21 In another study, Noyez et al. observed the economic issues and analysed multiple factors that are associated with rise in hospital expense like high risk patient's according to risk scoring systems, emergency surgery, total red cell units transfusion, invasive monitoring, duration of postoperative ventilation, length of ICU as well as hospital stay, incidence of postoperative arrhythmia and also wound infection.22

Few studies using the SF-36 questionnaire have presented only summarization of SF-36 scores as well as changes in physical and mental health status. 16-19, 23 Nonetheless, authors report changes in physical health status (PCS score derived from role physical, physical functioning, bodily pain, and general health) and also in mental health status (MCS score derived from vitality, role emotional, social functioning, and mental health). $.10-15,19,22$ In this study, we observed preoperative as well as postoperative functional score among all domains of health-related quality of life. Depending on several published articles, researcher can conclude that patients having greater operative risk score (EuroSCORE $\geq 6$ score) may have lower preoperative health-related quality of life score and are more likely to develop significant improvement in postoperative outcome if surgical procedure can be done safely. $\frac{3,5,18-23}{3}$ Furthermore, a patient with low or medium operative risk score (EuroSCORE), didn't observed significant changes in SF-36 scores. Moreover, patients with greater preoperative health -related quality of life don't have much space for improvement and their surgery is usually preventive in nature. $\underline{24}$ Though SF-36 score difference was higher in elderly population; however, no statistically significant dissimilarity of postoperative health-related quality of life was diagnosed among the patient aged $\leq 60$ years and $>60$ years, which was similar in the study by Lee and colleagues. $\underline{25}$

In this study, preoperative SF-36 scores of the younger population (age $\leq 60$ years) was higher, however, their contrast was higher in elderly population in perioperative SF-36 scores. We have observed that, this may be summarized as the period of one year following surgery is more beneficial for older than the younger age group of patients, even the major postoperative complications have been settled down. Nevertheless, all the 8 domains of health related quality of life have been observed and we came to a conclusion that quality of life of study population can be observed in details. As per observation the most convenient and useful tools for prediction of postoperative mortality and morbidity can be the SF-36 score in multivariate analysis. In spite of having some of the limitations like short duration with small sample size; however, this study can be useful for any kind of additional research and also can be beneficial for health-related quality of life advancement following heart surgery, especially for the older group of study population.

\section{Conclusion}

The preoperative health-related quality of life assessment using SF-36 questionnaire as well as operative risk scoring system should be a vital issue specifically in high-risk group of patients. Furthermore, in presence of low preoperative healthrelated quality of life; elderly patients most likely to have significant improvement in postoperative quality of life.

\section{Ethical Issue}

An informed written consent has been obtained from all of the participants.

\section{References}

1. Mandal S, Ghosh S, Rahman M, Majumder A, Ranjan R, Adhikary D, Hasan K, Islam MZ, Adhikary A. Health related quality of life among the coronary heart disease patients. Cardiovasc J. 2016; 9: 43-48.

2. Grady KL, Lee R, Subacius H, Malaisrie SC, McGee EC, Kruse J, Goldberger JJ, McCarthy PM. Improvements in health-related quality of life before and after isolated cardiac operations. Ann Thorac Surg. 2011; 91: 777-83.

3. Ranucci M, Castelvecchio S, Menicanti L, Frigiola A, Pelissero G. Accuracy, calibration and clinical performance of the EuroSCORE: Can we reduce the 
number of variables? Eur J Cardiothorac Surg. 2010; 37: 724-29.

4. Kolh P, Kerzmann A, Lahaye L, Gerard P, Limet R. Cardiac surgery in octogenarians: Perioperative outcome and long-term results. Eur Heart J. 2001; 22: $1235-43$

5. Shan L, Saxena A, McMahon R, Wilson A, Newcomb A. A systematic review on the quality of life benefits after aortic valve replacement in the elderly. J Thorac Cardiovasc Surg. 2013; 5: 1173-89.

6. Ware JE, Kosinsky M. Interpreting SF-36 summary health measures: A response. Qual Life Res. 2001; 5: 405-13.

7. Goldsmith IRA, Gregory YHL, Ramesh LP. A prospective study of changes in the quality of life of patients following mitral valve repair and replacement. Eur J Cardiothorac Surg. 2001; 11: 949-55.

8. Zuluaga MC, Guallar-Castilón P, Lopéz-García E, Banegas JR, Conde-Herrera M, Olcoz-Chiva M, Rodriguez-Pascual C, Rodriguez-Artaleho F. Generic and disease-specific quality of life as a predictor of long-term mortality in heart failure. Eur J Heart Fail. 2010; 12: 1372-78.

9. Frélich $M$, Štětka F, Pokorný $P$, Útrata $P$, Bedáňová $\mathrm{H}$, Ondrášek J, Pavlík P, Wagner R, Černý J. Cardiac surgery in elderly patients. Scripta Medica. 2003; 6: 341-46.

10. Engoren M, Arslanian-Engoren C, Steckel D, Neihardt J, Fenn-Buderer N. Cost, outcome, and functional status in octogenarians and septuagenarians after cardiac surgery. Chest 2002; 4: 1309 15.

11. Petr P, Vurm V, Soukupova A. Czech version of the SF - 36 questionnaires. Kontakt 2002; 1: 10-15.

12. Koertke H, Hoffmann-Koch A, Boethig D, Minami K, Breymann T, El-Arousy M, Seifert D, Koerfer R. Does the noise of mechanical heart valve prostheses affect quality of life as measured by the SF-36® questionnaire? Eur J Cardiothorac Surg. 2003; 7: 5258.

13. van den Berg MP, Hassink RJ, Tuinenburg AE, van Sonderen EFLP, Lefrandt JD, de Kam PJ, van Gelder IC, Smit AJ, Sanderman R, Crijns HJGM. Quality of life in patients with paroxysmal atrial fibrillation and its predictors: Importance of the autonomic nervous system. Eur Heart J. 2001; 3: 247 -53 .

14. Jensen BÖ, Hughes P, Rassmusen LS, Pendersen PU, Steinbruchel DA. Health-related quality of life following off-pump versus on-pump coronary artery bypass grafting in elderly moderate to highrisk patients: A randomized trial. Eur J Cardiothorac Surg. 2006; 8: 294-99.

15. Gjeilo KH, Wahba A, Klepstad P, Lydersen S, Stenseth R. Health-related quality of life three years after coronary surgery: A comparison with the general population. Scand Cardiovasc J. 2006; 1: 29 36.

16. Santini F, Montalbano G, Messina A, D'Onofrio A, Casali G, Viscardi F, Luciani GB, Mazzucco A. Survival and quality of life after repair of acute type A aortic dissection in patients aged 75 years and older justify intervention. Eur J Cardiothorac Surg. 2006; 3: 386-91.

17. Lönnerholm S, Blomström P, Nilsson L, Blomström -Lundqvist C. A high quality of life is maintained late after maze III surgery for atrial fibrillation. Eur J Cardiothorac Surg. 2009; 9: 558-62.

18. Hansen L, Winkel S, Kuhr J, Bader R, Bleese N, Riess FC. Factors influencing survival and postoperative quality of life after mitral valve reconstruction. Eur J Cardiothorac Surg. 2010; 3: 635-44.

19. Ware JE. SF-36 health survey update. Spine 2000; 24: 3130-39.

20. Rumsfeld JS, Magid DJ, O’Brien M. Changes in health-related quality of life following coronary artery bypass graft surgery. Ann Thorac Surg. 2001; 72: 2026-32.

21. Le Grand MR, Elliot PC, Murphy BM, Worcester MUC, Higgins RO, Ernest CS, Goble AJ. Health related quality of life trajectories and predictors following coronary artery bypass surgery. Health Qual Life Outcomes. 2006; 4: 1-13.

22. Noyez L, de Jager MJ, Markou AL. Quality of life after cardiac surgery: Under researched research. Interact Cardiovasc Thorac Surg. 2011; 13: 511-14.

23. Dumbor LN, Britchford G, Cale ARJ. The influence of an ageing population on care and clinical resource utilization in cardiac surgery. Br J Cardiol. 2011; 6: 28-32.

24. Beghé C, Wilson A, Ershler WB. Prevalence and outcomes of anemia in geriatrics: A systematic review of the literature. Am J Med. 2004; 7: 3-10.

25. Lee J, Govindan S, Celi LA, Khabbaz KR, Subramaniam B. Customized prediction of short length of stay following elective cardiac surgery in elderly patients using a genetic algorithm. World J Cardiovasc Surg. 2013; 3: 163-70. 